\title{
Sean C Sweetman (Ed): The Martindale, the complete dug reference, 37th edn
}

\author{
The Pharmaceutical Press, London-Chicago, 2011, ISBN 9780853699330
}

\author{
J. W. Foppe van Mil
}

Received: 4 July 2011 / Accepted: 11 July 2011 / Published online: 20 July 2011

(C) Springer Science+Business Media B.V. 2011

The publishing division of the Royal Pharmaceutical Society, the Pharmaceutical Press, has published a new version of their renown Martindale, which they name 'the Complete Drug Reference'. The content of the printed version is also available on-line, but for a separate fee through 'MedicinesComplete' (www.medicinescomplete.com). The first printed version of the book appeared in 1833 .

Despite the rapidly changing world of pharmaceuticals, Martindale continues to be internationally recognized as the reference for pharmacists in most areas of practice and research. In this version (37th edition) major changes are again made to ensure that the resource continues to meet needs of practitioners, researchers and academics.

- Changes to the index and the labeling of the volumes implemented to facilitate retrieval of information.

- Over 200 new drug monographs added and the coverage of proprietary preparations expanded to 41 countries and regions.

- New features added including access to Herbal ATC codes and the FDA's Unique Ingredient Identifiers, also known as UNII codes.

- For the first time purely homoeopathic preparations (a significant part of pharmacy practice in parts of Europe) are now listed in individual drug monographs as well as in the main Proprietary Preparations section of Martindale.
- Includes a new multilingual lexicon of pharmaceutical terms-essential with prescriptions now being valid across the EU. This should aid the non-native speaking reader when it comes to interpreting packaging, product information or prescriptions in the languages provided.

The book is split into two: one tome with the monographs, and one tome with preparations, manufacturers and indexes. The drug monographs are sorted by therapeutic groups, and each group has an introduction in which the rational pharmacotherapy of the area is discussed.

The book is indispensable for Drug Information Centres. All possible drugs can be retrieved, also the drugs that are not commercialised in ones own country, specific niche products or even homeopathic substances. The Martindale is also a very good tool for practicing pharmacists; they can retrieve many products by foreign brand names, and thus help clients to the right drugs or local equivalents.

However, it really is a setback in time that when buying the paper version, the content of the Martindale does not become available in an electronic version also. In times of electronic media, one would expect to buy a paper version of a book, together with the same information on DVD, or a time-limited on-line access. The publishers regrettably seem to have decided otherwise.

J. W. F. van Mil ( $)$

Zuidlaren, The Netherlands

e-mail: jwfvmil@vanmilconsultancy.nl 